\title{
Children's Allegations of Sexual Abuse: A Model for Forensic Assessment
}

\author{
William O'Donohue • Lorraine Benuto • \\ Matthew Fanetti
}

Received: 10 August 2009/Accepted: 15 December 2009/Published online: 5 June 2010

(C) Springer Science+Business Media, LLC 2010

\begin{abstract}
It is important both clinically and forensically to gain information to provide an understanding of the veracity of a child's allegations of sexual abuse. Even though it is reasonable to hypothesize that most allegations are true-children are not infallible and thus some allegations are false. A systematic model of pathways to false allegations - however rare or common - is important because so much depends on this question (i.e., both false positives and false negatives are harmful to children). We propose that there are two major pathways to false allegations of child sexual abuse: (1) the child is lying and (2) the child has a false memory due to his or her problems in information processing. We conclude by presenting a more detailed protocol for more formally evaluating these pathways to false allegations in specific cases.
\end{abstract}

Keywords Sexual abuse Child sexual abuse .

Forensic assessment

When children make allegations of sexual abuse, the legal system immediately becomes involved as the child is alleging that he or she is a victim of a felony. The legal system rightly views the crime of sexually abusing a child as one of its most serious matters as hurting a child in this way is seen as one of the heinous crimes. In addition, it is important that these allegations are quickly and carefully

W. O’Donohue $(\bowtie) \cdot$ L. Benuto

Department of Psychology/296, University of Nevada,

Reno, NV 89557, USA

e-mail:wto@unr.edu

M. Fanetti

Missouri State University,

Springfield, MO, USA investigated as the child may be vulnerable to further molestation by the perpetrator or the perpetrator may have abused other children in the past or may abuse other children in the future if they are not quickly apprehended. As part of society's revulsion toward child sexual abuse, the sentences for this crime are often the longest, often eclipsing sentences for murder. For example, in Nevada, the sentence for sexual penetration of a child is 35 years without any chance for parole, probation, or time off for good behavior.

In the past few decades, epidemiological studies have shown that child sexual abuse is more frequent than both the field and the layperson previously thought. In fact, the Centers for Disease Control (2005) have indicated nearly a $21 \%$ prevalence rate of childhood sexual abuse in the USA. Also, although the sequealea of abuse range widely (e.g., Bagley 1996; Campbell et al. 2009; Holmes and Slap 1998; Messman-Moore and Long 2003; Paras et al. 2009), children who are sexually abused often experience psychological and social disturbances that include PTSD (Kingston and Raghavan 2009), depression (Shea 2008), substance abuse (Kingston and Raghavan 2009; Pirard et al. 2005), and sexual acting out (Taylor 1998). In fact, problems such as those cited above can be lifelong (Draper et al. 2008).

However, some others have expressed concern that the pendulum has swung too far - that there is now a hysteria about child sexual abuse (Ceci and Bruck 2006). There are several infamous cases (McMartin, Kelly Michaels, Edenton) in which the state has prosecuted individuals on what is commonly viewed as very problematic allegations of children. In the McMartin case, the trial lasted 3 years (1987 to 1990) and was at that date the most expensive prosecution in the history of California. However, the jury was hung and a mistrial declared, primarily due to the problematic interviewing techniques and the unusual features 
of some of the allegations of the children (e.g., flushed down toilets to secret rooms; witnessing witches fly). Nonetheless, one of the accused, Raymond Buckley, was incarcerated for most of the trial time. In another case, Kelly Michaels, a 25year-old daycare worker in New Jersey, was found guilty of several counts of child sexual abuse and served 5 years in prison, until the case was reopened due to the efforts of two investigative reporters. Appellate court ruled that the prosecutor in this case used coercive methods contrary to accepted child interviewing procedures. Kelly Michaels' conviction was overturned, and she filed a suit against her prosecutor for prosecutorial misconduct which was settled out of court. In the Edenton, $\mathrm{NC}$ case, several male and female daycare workers were charged with engaging in orgies with numerous children despite some of the allegations being relatively bizarre (i.e., murder of babies, torture and being thrown into a school of sharks). These individuals were convicted and several remain in prison.

This is not to say that most allegations made by children that they were sexually abused are false. It seems most plausible to conclude that most allegations that children make are true. Part of the problem is that child sexual abuse is usually a witnessless crime and there are rarely markers or definitive evidence (Sbraga and O'Donohue 2003). However, this is not to say all allegations are true. At a minimum, children, like adults, are capable of making errors in their assertions. It is the purpose of this paper to elucidate the major pathways for false allegations of sexual abuse and a forensic protocol to track the presence or absence of these pathways. To date, the construction of such a model has not been achieved. A potential value of this model is not only theoretical to gain a basic understanding of the phenomenon of false allegations, but it can also serve as a practical guide to structure forensic analyses of child sexual abuse allegations.

This subject - that some allegations of sexual abuse made by children are false - is admittedly controversial. It may be the case that there are some in this field who either disagree with this claim (although arguing for the infallibility of children would seem to be a rather difficult task) or more likely just to ignore this possibility as an "inconvenient truth." However, we believe that a systematic analysis of this phenomenon-however rare or common-is important because so much rides on this question. It is important to note that a thoroughgoing commitment to the welfare of the child that both a false positive and a false negative are harmful to the child. A false positive-believing that the child is a sexual abuse victim when they are not-is harmful to the child's self-concept and their autobiographical understanding of themselves is changed; others may treat them differently - and perhaps their understanding of a key person in their life (e.g., their stepfather) is changed in a negative direction. In addition, of course, if the prosecution is successful, it can cause severe harm to the adult who is falsely accused. Responsible professionals need to be concerned about both kinds of errors.

\section{A Model of the Pathways to False Allegations of Child Sexual Abuse}

There are two major pathways to a false allegation: the child is lying or the child's information processing has been biased or is in error (O'Donohue and Fanetti 1996). The latter pathway, although is broad and gives rise to several specific subpathways, will be discussed in the next section.

\section{The Child is Lying}

Children do not always tell the truth. It is not the case that there are special topics - such as their own abuse-in which children are incapable of lying. As a field, we know little about the variables that cause children to lie or tell the truth. Researchers have suggested that personality variables, habit (Lowenstein 1994), a developing central nervous system, a congenitally acquired defect in the central nervous system, the presence of an emotional disturbance, the desire to please others (i.e., parents, therapists, lawyers; Kaplan 1990), and behavioral disorders (such as conduct disorder and oppositional defiant disorder; Webster-Stratton and Dahl 1995) may contribute to a child lying and thus result in an invalid statement. This aside, we do not know the frequency at which children lie in general. It would be useful to have such norms and more specifically norms about lying about child sexual abuse. However, the construction of these norms would be difficult as they would require an almost God-like knowledge of what the truth of the matter actually is -i.e., the ultimate issue.

Although lying is not a frequent pathway, lying about child sexual abuse does occur. Children at times recant (see Bradley and Wood 1996). Thus, children sometimes claim that they have previously lied or at least were mistaken. It would seem implausible that every one of these recantations of original abuse accusations is false.

\section{Child Has a False Memory Due to Problems in Information Processing}

\section{Biased Interactions, Including Forensic Interviews}

No one has done more to elucidate this pathway than Steven Ceci and Maggie Bruck (1995, 2006, 2007). These authors have concluded that although children can give accurate reports, children's memory and reports are also malleable and particularly influenceable by adults. They define a biased interaction or biased interview with a child 
as one in which the interviewer has preconceived ideas about the truth of the matter and acts in such a way as to influence the child in this direction.

There are more than 100 studies investigating the myriad of ways (e.g., repeated questioning, leading questions, social conformity press) shown to influence false allegations that adults can influence children to make false allegations (Ceci and Bruck 1995; Fivush and Schwarzmueller 1995; Memon and Vartoukian 1996). Tactics for influencing children range from subtle to not-so-discreet. For example, parents can (often inadvertently) subtly suggest false information to their children who end up incorporating this post-event information into their memories and making false allegations.

The following study illustrates such an example. Poole and Lindsay (1995) had preschool-aged children witness four science demonstrations in a university laboratory. Four months later, parents were mailed stories that contained descriptions of their children's visit to the lab. Two of the stories were true and two were false (i.e., described experiments that the children had not seen). Each story finished with a fabricated account of what happened when it was time to leave the lab: "Mr. Science wiped (child's name) hands and face with a wet-wipe. The cloth got close to (child's name) mouth and tasted really yucky." Parents read the story to their children three times. Later, children told the experimenters that they had participated in demonstrations that they had not (i.e., the false stories read by their parents). More than half of the participants said that Mr. Science had wiped their mouths and many elaborated on their "yes" answers. When asked if Mr. Science had actually wiped their mouths or did their mother just read the story, $71 \%$ of the children maintained that it really happened. This study was replicated (Poole and Lindsay 1996) using children from a wider age range (3- to 8-year-olds). Findings were similar, except they found that when asked if Mr. Science wiped their mouths or if their mother just read the story, the older children tended to recant their claims and said that their mother told them.

A study that highlights the problems of child witnesses who are interviewed for testimony is the "Sam Stone" study conducted by Ceci and Leichtman (1992). Young children were told that a visitor, Sam Stone, was clumsy and always broke things that were not his. When "Sam" came to visit, he did not touch or break anything. The next day, the children saw a soiled stuffed bear and a torn book. Even though no child had seen Sam do anything, when asked, $25 \%$ hinted that he might have had a part in the problem. Over the next 10 weeks, they were asked misleading questions/statements by the first interviewer, such as, "I wonder if Sam Stone got the teddy bear dirty on purpose or by accident?" On the tenth week, a second (seemingly independent) interviewer asked what had happened to the toys. Seventy-two percent of the children overtly accused
Sam of having ruined the toys, and $45 \%$ reported remembering having seen Sam do it.

Another study conducted by Clarke-Stewart et al. (1989) sought to determine whether or not a reported memory for observed events could be changed by suggestions made by an authoritative adult. Three groups on children observed a janitor, Chester. One group saw a working janitor, the second group saw a playing janitor, and the third group saw a janitor who was playing mildly suggestively with a doll. The "playing" Chester bribed the children with candy not to tell his boss that he had been playing instead of working. Shortly thereafter, the children were questioned by Chester's boss. The children were asked what Chester had been doing. Initially, gentle suggestions were made opposite to the child's actual observations. If the child observed a working Chester, the boss suggested he might have been playing, and vice versa. Twenty-five percent of the children changed their story after the initial suggestions. After stronger suggestions were made, every child changed stories to be inconsistent with their observations and consistent with the suggestion. In fact, they did not revert their stories when later asked about the incident by their parents who were unaware of the child's actual observations or the direction of the suggestions made. This indicates that not only did the children respond to the suggestion, but they also have seemed to have incorporated the details into their report on a longer-term basis. The above studies are just a few from a fairly large body of literature that suggest that children are suggestible (O'Donohue, Tolle, and Benuto, in preparation).

Fanetti et al. (2006) have developed the Protocol for the Forensic Evaluation of Children which lists major interviewing errors. Fanetti, O'Donohue, and Bradley have suggested that there are 18 factors which may cause the child to make a false report:

1. The child, due to rapport problems, may not have been comfortable and therefore may not have answered in a complete and accurate manner.

2. The child did not know that she could say, "I don't know" when she did not know the truth.

3. The child did not understand what it means to tell the truth.

4. The child did not know the importance of telling the truth.

5. The child did not understand her role in the interview or the purpose of the interview and therefore her answers may have been distorted.

6. The child might have felt uncomfortable discussing certain topics with the interviewer, therefore may not have answered in a complete and accurate manner.

7. The child had experienced some sort of externally derived threatening experience, which may have served to distort answers (e.g., fear of threats to self, loved ones, or property). 
8. The child did not feel as though she had a choice in the type of responses she provided.

9. The child answered in a certain way in an attempt to please an authority figure.

10. There were leading questions.

11. The child's verbalizations at times were disconfirmed.

12. The interviewer inappropriately reinforced certain types of answers.

13. There were repetitive and perhaps coercive questions.

14. There were aspects of the child's total response (e.g., body posture, facial expressions, etc.) that gave a different interpretation to the child's answer.

15. The interviewer encouraged the child to speculate about important details after the child has indicated that she was not sure about an answer or did not have the information.

16. The interviewer referenced the fact that other individuals (e.g., peers) had been interviewed regarding the interview topic and/or indicated what the other individuals' responses were.

17. The interviewer focused or redirected the child toward information about a specific detail or individual

18. The child's report has been contaminated by some outside source, such as experience with another professional (e.g., retroactive interference from some other interviews.

It is important to note the following:

1. When all factors are ruled out, the interview should be considered free from basic bias, but that does not mean that the child's report is accurate or inaccurate.

2. When some or all of the biasing influences are identified in an interview, the interview cannot be considered free from potential bias. Once again, the child's testimony can still be accurate or inaccurate regardless of the presence of bias. However, the presence of one of these potentially biasing factors creates a rival alternative hypothesis: the child's report may be due to this factor rather than straightforward memory retrieval.

Understanding the two major pathways in this model implies a strategy to assess their relevance in forensic cases. We turn now to this task.

\section{History of Lying}

One dimension that can be assessed is whether the child has a history of lying that is abnormal or unusual. There are a variety of ways to gather information relevant to this pathway. A review of records should address the question of whether the child has made allegations that were found to be false in the past. Do teachers note in school records that the child has a history of lying in school (e.g., making up allegations against other children)? Have parents noted this or sought treatment for lying? Do others who know the children well, especially those that have no stake in the case, report this or its opposite? This kind of information is not definitive, but it is relevant. The mental health professional can present this kind of information to the trier of fact so that they have a more complete understanding of the dynamics of the case. No indications of any past history with lying ought to have some role in deciding the child's propensity to be lying in this situation.

\section{The Allegation Contains Fantastical Details}

Fantastical details are regarded as one of the hallmarks of a problematic allegation because fantastical details establish that at least part of the child's report is false (Ceci and Bruck 2006). When children report things that cannot possibly be true, e.g., that there are secret rooms below the toilet where abuse occurred, that they were stabbed multiple times although there are no scars; that they were flown in airplanes over the ocean and saw babies fed to sharks in the few hours they were at daycare. Again, this does not mean that other parts of their report that do not contain these inconsistencies are false, but the presence of fantastical details is relevant to the credibility of the child's allegations. Most allegations of abuse do not contain these fantastical details (Ceci and Bruck 2006). The forensic assessment of the child's allegations should rule in or rule out the presence of fantastical details.

\section{The Child's Allegations Contain Logistical Implausibilities}

Logistical implausibilities are less improbable than the fantastic details; however, these details still are highly improbable. These are relevant to an assessment of the child's report because these still shed light on the credibility of the child's allegations. Examples of logistical improbabilities are statements such as: the perpetrator had anal sex with the young child for the first time and no lubricants were used but that it did not hurt; that prolonged sexual abuse occurred a few feet away from non-abusing noncomplicit adults with an open door between them; or the abuse occurred in the daylight in a fairly public place. In addition, a child's report may contain other implausibilities, i.e., green material that glowed in the dark came out of the alleged perpetrator's penis; or the physical positions of the two parties do not make sense given the allegations (e.g., the child was on his knees and the perpetrator standing up when the perpetrator's penis entered her vagina). Again, 
these should not be considered as markers of false allegations, but they do give rise to legitimate questions about the coherence of the child's allegations which triers of fact should consider. In the forensic assessment of the allegations, the presence or absence of this should be noted.

\section{Impoverished Descriptions of the Abuse}

At times, children give detailed descriptions of their abuse. They can describe in an age appropriate manner events that occurred before, during, and after in a way that makes a coherent, understandable narrative. However, in some instances, the abuse details are significantly impoverished. This can range from the entire allegation containing only a simple declaration such as "he abused me" or "he touched me" to an only slightly detailed allegation, e.g., "he put his fingers inside me." However, the child cannot provide any additional age-appropriate details about the abuse (How long did it occur? How many times did he do this? Where did it occur? What did the perpetrator do immediately before this? What did the perpetrator do immediately after this? How did it feel?). If the child cannot answer these questions, this should be noted for the trier of fact. In the forensic assessment, one has to be sure that there are no other reasons for this impoverished account, e.g., no cognitive impairment; no drugs given to the child. However, failing this, it is important for the forensic examiner to note that the child's allegations are missing a richness of detail that is more commonly found in these allegations. The concern, of course, is that the child cannot give these details because the report is not a normal retrieved memory.

\section{Inconsistencies in the Child's Allegations}

The degree to which the child's allegations are internally consistent and consistent across time is also important to assess in the forensic context. It is reasonable to hypothesize that true allegations are consistent. If a child contradicts him or herself within an interview, then the interviewer should note this and attempt to resolve the inconsistency (i.e., discover which account the child wants to commit to) as well as attempt to have an understanding of why the child's account is inconsistent in this telling (e.g., perhaps the child did not understand the question; perhaps the child's memory is now clearer). In addition, a forensic assessment of the child's allegations should attempt to determine how consistent the allegations are across tellings and possible reasons for these inconsistencies. For example, a child may say that a particular abusive act happened exactly two times and then latter say it happened hundreds of times. This is inconsistent, and, although again not a marker of a false allegation, both statements, by logic, cannot be true. It is also recommended that a distinction be made concerning core details and peripheral details when evaluating these inconsistencies. Inconsistencies about peripheral details (he was wearing blue shoes and he was wearing red shoes) should be seen as much less important than inconsistencies about core details. Core details are descriptors of the abuse itself - the who, what, when, where, and how details. Of particular concern is when the child is never consistent, i.e., in each telling, including perhaps in testimony during the trial, the child again changes the allegations in core detail. This is sometimes called a "blossoming allegation"-in each telling, there is more detail despite the fact that the previous narrative was thought to be complete. Thus, it is critical that in the forensic evaluation of the allegations, the degree and kinds of inconsistencies, if any, are documented for the trier of fact.

\section{Stake Analysis}

This issue concerns if anyone appears to have a stake in the allegations or in a guilty or not guilty verdict in the trial. By stake, we mean something like a hidden agenda. It is reasonable for adults to have a legitimate stake in the truth being determined and for the child to be safe and protected. However, sometimes it is the case that there are more complex motivations surrounding the allegation. Is there an adult who has contact with the child who has a vendetta against the accused? Is there an acrimonious divorce in which one parent seems to detest the other parent? Is there someone (an aunt) who wants custody of the children? Is there someone who will financially profit from an outcome of the trial? Has this individual had access to the child where they might have employed suggestive questioning to alter the child's information processing and thus help create a potentially false allegation? Again, in the forensic evaluation, the evaluator should determine if there are parties who may have agenda regarding the abuse allegations. If there are, further analysis is necessary to determine if they might have had an influence on the child. Forensic interviews of the child should also investigate this possibility.

\section{Outcry Analysis}

The general circumstances of the child's initial outcry should be determined. There are circumstances that do not give rise to alternative rival hypotheses, i.e., the child spontaneously told a parent or the child reported pain that was followed up to be injuries consistent with abuse. However, there are other circumstances of the initial outcry that give rise to plausible hypotheses that need to be further 
investigated. Did the child initially make the outcry after seeing secondary gain from another child's allegation? Did the child make the outcry in a form of therapy that might be coercive, e.g., recovered memory therapy (Loftus and Davis 2006)? Did the child make an outcry after being repeatedly questioned over several episodes by a parent? Did the child's outcry come in a game of truth or dare or one upmanship with peers? Again, the presence of these unusual circumstances for an initial outcry does not definitively indicate that the allegations are false. However, their presence is relevant to the trier of fact as they give rise to other hypotheses for the allegation.

\section{Conclusions}

This paper has attempted to analyze the phenomenon of false allegations of sexual abuse that are made by a child. Although it, in all probability, will be difficult to ever determine the frequency of these since we will not have access to the ground truth, it is reasonable to assume that these sometimes occur. These false allegations can hurt a number of individuals - not the least is the child making these.

We suggest that there are two major pathways to false allegations: (1) that the child is lying and (2) that the child's information processing has been altered or biased in some ways, and we give specific pathways that this may occur. In addition, we suggest that it can be invaluable to the trier of fact that these pathways be evaluated to rule in or rule out their presence in a particular case. This evaluation will not result in definitive statements about whether the allegations are true or false - this is the ultimate question and up to the judge or jury to decide. However, we believe that this information will allow a more complete understanding of the allegations and their context and could lead to more accurate determinations.

This model should be empirically evaluated. It will be difficult again to do this given the criterion problem - there is no ultimate gold standard to determine the truth of these allegations. However, it might be possible to examine verdicts in trials as proxies for these, or for CPS decisions regarding the foundness of cases and determine to what extent these model correlates with these. Ultimately, this model might need to be weighted in a regression equation to determine the quantitative role of each pathway.

\section{References}

Bagley, C. (1996). A typology of child sexual abuse: The interaction of emotional, physical and sexual abuse as predictors of adult psychiatric sequelae in women. Canadian Journal of Human Sexuality, 5(2), 101-112.
Bradley, A. R., \& Wood, J. M. (1996). How do children tell? The disclosure process in child sexual abuse. Child Abuse \& Neglect, 20(9), 881-891.

Campbell, R., Dworkin, E., \& Cabral, G. (2009). An ecological model of the impact of sexual assault on women's mental health. Trauma, Violence \& Abuse, 10(3), 225-246.

Ceci, SJ, \& Bruck, M. (1995). The effects of repeated questioning. In Jeopardy in the courtroom: A scientific analysis of children's testimony (pp. 107-125). Washington: American Psychological Association.

Ceci, S. J., \& Bruck, M. (2006). Children's suggestibility: Characteristics and mechanisms. In R. V. Kail (Ed.), Advances in child development and behavior, vol. 34 (pp. 247-281). San Diego: Elsevier Academic.

Ceci, S. J., \& Bruck, M. (2007). Loftus's lineage in developmental forensic research: Six scientific misconceptions about children's suggestibility. In M. Garry \& H. Hayne (Eds.), Do justice and let the sky fall: Elizabeth Loftus and her contributions to science, law, and academic freedom (pp. 65-77). Mahwah: Erlbaum.

Ceci, S. J., \& Leichtman, M. D. (1992). I know that you know that I know that you broke the toy: a brief report of recursive awareness among 3-year-olds. In S. J. Ceci, M. D. Leichtman, \& M. Putnick (Eds.), Cognitive and social factors in early deception (pp. 1-9). Hillsdale: Erlbaum.

Centers for Disease Control (2005). Prevalence of individual adverse childhood experiences. Retrieved from http://www.cdc.gov/ nccdphp/ace/prevalence.htm.

Clarke-Stewart, A., Thompson, W., \& Lepore, S. (1989). Manipulating children's interpretations through interrogation. Paper presented at the Biannual Meeting of the Society for Research on Child Development, Kansas City, MO, May 2.

Draper, B., Pfaff, J. J., Pirkis, J., Snowdon, J., Lautenschlager, N. T., Wilson, I., et al. (2008). Long-term effects of childhood abuse on the quality of life and health of older people: Results from the depression and early prevention of suicide in general practice project. Journal of the American Geriatrics Society, 56(2), 262-271.

Fanetti, M. N., O'Donohue, W. T., \& Bradley, A. R. (2006). A method for evaluating child forensic interviews. American Journal of Forensic Psychology, 24(3), 5-27.

Fivush, R., \& Schwarzmueller, A. (1995). Say it once again: Effects of repeated questions on children's event recall. Journal of Traumatic Stress, 8(4), 555-580.

Holmes, W. C., \& Slap, G. B. (1998). Sexual abuse of boys: Definition, prevalence, correlates, sequelae, and management. JAMA: Journal of the American Medical Association, 280(21), $1855-1862$.

Kaplan, J. M. (1990). Children don't always tell the truth. Journal of Forensic Sciences, 35(3), 661-667.

Kingston, S., \& Raghavan, C. (2009). The relationship of sexual abuse, early initiation of substance use, and adolescent trauma to PTSD. Journal of Traumatic Stress, 22(1), 65-68.

Loftus, E., \& Davis, D. (2006). Recovered memories. Annual Review of Clinical Psychology, 2, 469-498.

Lowenstein, L. F. (1994). Why children lie: How to prevent and to curtail it. Criminologist, 18(1), 11-22.

Memon, A., \& Vartoukian, R. (1996). The effects of repeated questioning on young children's eyewitness testimony. British Journal of Psychology, 87(3), 403-415.

Messman-Moore, T. L., \& Long, P. J. (2003). The role of childhood sexual abuse sequelae in the sexual revictimization of women: An empirical review and theoretical reformulation. Clinical Psychology Review, 23(4), 537-571.

O'Donohue, W., \& Fanetti, M. (1996). Assessing the occurrence of child sexual abuse: An information processing, hypothesis testing approach. Aggression and Violent Behavior, 1(3), 269281. 
Paras, M. L., Murad, M. H., Chen, L. P., Goranson, E. N., Sattler, A. L., Colbenson, K. M., et al. (2009). Sexual abuse and lifetime diagnosis of somatic disorders: A systematic review and metaanalysis. JAMA: Journal of the American Medical Association, 302(5), 550-561.

Pirard, S., Sharon, E., Kang, S. K., Angarita, G. A., \& Gastfriend, D. R. (2005). Prevalence of physical and sexual abuse among substance abuse patients and impact on treatment outcomes. Drug and Alcohol Dependence, 78, 57-64.

Poole, D. A., \& Lindsay, D. S. (1995). Interviewing preschoolers: Effects of nonsuggestive techniques, parental coaching, and leading questions on reports of nonexperienced events. Journal of Experimental Child Psychology, 60(1), 129-154.

Poole, D. A., \& Lindsay, D. S. (1996). Effects of parents. suggestions, interviewing techniques, and age on young children.s event reports. Presented at NATO Adv. Study Inst. Recollect. Trauma: Sci. Res. Clin. Practice. Port de Bourgenay, France.

Sbraga, T. P., \& O'Donohue, W. (2003). Post hoc reasoning in possible cases of child sexual abuse: Symptoms of inconclusive origins. Clinical Psychology: Science and Practice, 10(3), $320-334$.

Shea, D. J. (2008). Effects of sexual abuse by Catholic priests on adults victimized as children. Sexual Addiction \& Compulsivity, 15(3), 250-268.

Taylor, P. E. N. (1998). The relationship of child and adolescent sexual abuse with symptomatology: A meta-analytic and narrative review. USA: ProQuest Information \& Learning.

Webster-Stratton, C., \& Dahl, R. W. (1995). Conduct disorder. In M. Hersen \& R. T. Ammerman (Eds.), Advanced abnormal child psychology (pp. 333-352). Hillsdale: Erlbaum. 